\title{
Three-Echelon Green Supply Chain Inventory Decision for Imperfect Quality Deteriorating Items
}

\author{
Yosef Daryanto \\ Department of Industrial Engineering, Universitas Atma Jaya Yogyakarta, \\ Jl. Babarsari 43, Yogyakarta, Indonesia \\ Email: yosef.daryanto@uajy.ac.id
}

\author{
Hui Ming Wee \\ Department of Industrial \& Systems Engineering, Chung Yuan Christian University, \\ Chung-Pei Road No 200, Chung-li City, 32023, Taiwan \\ Email: weehm@cycu.edu.tw (Corresponding Author)
}

\begin{abstract}
This paper presents an integrated supply chain inventory model for deteriorating items with an imperfect quality considering its environmental impact, particularly the supply chain carbon footprint. An imperfect production system produces a certain number of defective items. Therefore, in our model, the manufacturer conducts a $100 \%$ quality check to prevent the delivery of defective items. A third-party logistics (3PL) company supports the logistics between the manufacturer and the buyer, by transporting the products from the manufacturer to a warehouse and then delivering the products in a smaller quantity to the buyer. The proposed solution procedure determines the number of deliveries per cycle, delivery interval, and delivery quantity between the 3PL and the buyer simultaneously. It also determines the production quantity of the manufacturer and the delivery quantity from the manufacturer to the 3PL. The objective is to minimize the expected total cost and to reduce total carbon emissions.
\end{abstract}

Keywords: carbon emission, imperfect quality, deteriorating items, supply chain inventory

\section{INTRODUCTION}

The reduction of supply chain environmental effects has received massive attention. Researchers and practitioners consider sustainable supply chain management practices to reduce the environmental effect (e.g., total carbon emissions) without forfeiting the primary objective of minimizing cost or maximizing financial profit. Anderson et al. (2020) identified a positive correlation between the supply chain's environmental and socially responsible activities with the financial performance although the effects are different for each supply chain. Supply chain inventory control can be combined with a green growth perspective to support companies' sustainable operations (Wang et al., 2019). However, the implementation of carbon pricing does not guarantee a reduction in global emission (Fang et al., 2020); this call for wise and innovative supply chain decision.

Carbon emissions come from various supply chain activities, including freight transport, material handling, and storage (McKinnon, 2018). Hua et al. (2016) considered carbon emissions from order shipment, inventory holding, and item deterioration in an order quantity model. Dwicahyani et al. (2017) considered emission and energy usage from production, remanufacturing, and transportation activities in a closed-loop supply chain. Wangsa (2017) incorporated emissions from production and transportation. Daryanto \& Wee (2018) considered emissions from fuel combustion during transportation, from electricity consumption in inventory holding, and emissions from disposing of deteriorated items.

Other research extended the low-carbon supply chain inventory model, incorporating the existence of imperfect quality items. Wahab et al. (2011) and Jauhari et al. (2014) considered the return of defective products from the buyer to the vendor and incorporated tracking carbon emissions. Jauhari \& Laksono (2017) extended the model, assuming that the manufacturer provides a warranty for defective products. Further, the model considered a fuzzy demand rate and an adjustable production rate. Recently, Tiwari et al. (2018) and Daryanto et al. (2019b) incorporated the effect of defective products and carbon emissions for deteriorating items in an integrated two-echelon supply chain.

This study extends previous research by simultaneously considering the effect of a carbon emission tax, imperfect quality, and item deterioration in a threeechelon supply chain. Specifically, this paper extends Daryanto et al.'s (2019a) three-echelon supply chain model, which consists of a manufacturer, third-party logistics (3PL) service provider, and buyer. The present paper also considers the effect of imperfect quality products. Quality inspection is carried out by the manufacturer to prevent the delivery of defective products. This inspection is performed just after production, similar to Sarkar et al. (2017). Also, this paper assumes that the 3PL performs all transportation activities. The model also considers carbon emissions from energy consumption in production, fuel consumption in transportation, energy consumption in warehousing, and disposal activities.

This research contributes to the theoretical knowledge of low-carbon supply chain models to reduce supply chain carbon emissions. Practically, this model can help managers decide the number of deliveries per cycle, delivery interval, and delivery quantity between the 3PL and buyer 
simultaneously when carbon tax regulation exists. This model can also determine the manufacturer's production quantity and the delivery quantity from the manufacturer to the 3PL.

\section{LITERATURE REVIEW}

Integration and coordination among supply chain members is an essential practice in supply chain management. In an integrated supply chain, members jointly make decisions through communication and information sharing. Previous research has shown the advantage of supply chain integration in reducing total cost and optimizing profit. Khan \& Wisner (2019) identified a significant correlation between supply chain integration and organizational learning that will affect supply chain responsiveness and flexibility, and which will ultimately impact firm performance.

Recently, research on green supply chain management has also shown the benefit of supply chain integration in terms of enhancing environmental performance (Tseng et al., 2019). A green supply chain management (GSCM) integrates environmental concerns such as waste, pollution, and emissions into supply chain management practices (Sarkis, 2012). Mishra et al. (2020) investigated carbon emissions and solid waste from end-of-life goods, while Das et al. (2020) considered water footprint and supplier's social risk, and developed a holistic sustainable supply chain. In literature, many quantitative and qualitative management tools can be used in modelling and developing a green supply chain (Tundys, 2018). Research and publication on GSCM have emerged since the 1990s and have had exponential growth since 2010 until the present (Tseng et al., 2019). GSCM includes the application of environmental management principles, reverse logistics, recycling and remanufacturing, closed-loop supply chains, and low carbon supply chain management (LCSCM). Currently, LCSCM is gaining widespread attention because supply chain activities such as sourcing, production, warehousing, and distribution are massive sources of greenhouse gas emissions, including carbon dioxide. The aim is to reduce the overall carbon emissions of supply chains (Das \& Jharkharia, 2018). LCSCM research includes studies of supply chain inventory management. In these studies, the optimization model has been reformulated, for which the objective function is to maximize total profit or minimize the total cost and total carbon emissions.

Wahab et al. (2011) and Chen \& Hao (2015) examined the total cost of a two-echelon supply chain with and without carbon emissions consideration. Other researchers have studied supply chain inventory models for different carbon pricing systems such as incorporating a carbon tax, emission cap, and emission trading (Jaber et al., 2013; Benjaafar et al., 2013; Hammami et al., 2015). A carbon tax system penalizes the number of carbon emissions emitted by a firm based on a local/national/regional tax rate. An emission cap system strictly limits the emitted carbon emissions by a firm. In contrast, carbon emission trading allows a firm to exceed their predetermined cap by buying an excess quota from other firms. The effect of different coordination mechanisms such as vendor-managed inventory on LCSCM has been incorporated by Zanoni et al. (2014), Bazan et al. (2015), Bazan et al. (2017), Marchi et al. (2019), and Bai et al. (2019). Hariga et al. (2017) and Shamayleh et al. (2019) studied LCSCM for cold product supply chains, which require specialized equipment to maintain reduced temperatures, which consume a considerable amount of electricity. Aljazzar et al. (2018) and Sarkar et al. (2018) studied the impact of a trade credit scenario on carbon emissions reduction. Alhaj et al. (2016) and Gosh et al. (2018) developed the LSCM model with uncertain customer demand. The effect of defective items on LCSCM has been studied by Jauhari et al. (2014), Sarkar et al. (2016b), and Sarkar et al. (2018). Daryanto \& Wee (2018) considered the effect of deterioration rate on total cost and emissions in a two-echelon low-carbon supply chain. The study considered indirect carbon emissions from warehousing energy usage and direct carbon emissions from fuel combustion during order deliveries and disposal of deteriorated items. Tiwari et al. (2018) added the impact of imperfect quality. Further, Daryanto et al. (2019a) extended the study to a three-echelon low-carbon supply chain.

In many cases, a company produces a percentage of imperfect quality products during out-of-control production processes or due to imperfect materials and inappropriate handling. The effect of imperfect quality on supply chain inventory model has been studied by many researchers such as Huang (2002, 2004), Goyal et al. (2003), Wee et al. (2006), Giri \& Chakraborty (2011), Wahab et al. (2011), Jauhari et al. (2014), Lee \& Kim (2014), Sarkar et al. (2016a), and Yu \& Hsu (2017), assuming that the buyer performs the quality inspection. Khouja (2003), Bazan et al. (2014), Sarkar et al. (2017), and Marchi et al. (2019) incorporated quality screening by the manufacturer to prevent the delivery of imperfect quality products. Recently, Daryanto et al. (2019b) examined carbon emissions reduction when an inspection is performed by the manufacturer instead of the buyer, although, a trade-off between carbon emissions reduction and cost-saving may occur. In this situation, management's willingness and commitment to reducing total carbon emissions are needed. The contribution of previous authors and this paper is presented in Table 1.

$\underline{\text { Table } 1 \text { Contribution of selected literature and the proposed model }}$

\begin{tabular}{|c|c|c|c|c|c|c|}
\hline \multirow{2}{*}{ Authors } & \multirow{2}{*}{$\begin{array}{l}\text { Two-echelon } \\
\text { supply chain }\end{array}$} & \multirow{2}{*}{$\begin{array}{l}\text { Three-echelon } \\
\text { supply chain }\end{array}$} & \multicolumn{2}{|c|}{ Inspection } & \multirow{2}{*}{ Deteriorating items } & \multirow{2}{*}{$\begin{array}{c}\text { Carbon } \\
\text { emissions }\end{array}$} \\
\hline & & & Buyer & Vendor & & \\
\hline Huang (2002) & Yes & & Yes & & & \\
\hline Goyal et al. (2003) & Yes & & Yes & & & \\
\hline Wee et al. (2006) & Yes & & Yes & & Yes & \\
\hline Giri \& Chakraborty (2011) & Yes & & Yes & & Yes & \\
\hline Wahab et al. (2011) & Yes & & Yes & & & Yes \\
\hline
\end{tabular}


Table 2 Contribution of selected literature and the proposed model (cont')

\begin{tabular}{|c|c|c|c|c|c|c|}
\hline \multirow{2}{*}{ Authors } & \multirow{2}{*}{$\begin{array}{l}\text { Two-echelon } \\
\text { supply chain }\end{array}$} & \multirow{2}{*}{$\begin{array}{l}\text { Three-echelon } \\
\text { supply chain }\end{array}$} & \multicolumn{2}{|c|}{ Inspection } & \multirow{2}{*}{ Deteriorating items } & \multirow{2}{*}{$\begin{array}{l}\text { Carbon } \\
\text { emissions }\end{array}$} \\
\hline & & & Buyer & Vendor & & \\
\hline Wang et al. (2011) & & Yes & & & Yes & \\
\hline Jauhari et al. (2014) & Yes & & Yes & & & Yes \\
\hline Zanoni et al. (2014) & Yes & & & & & Yes \\
\hline Lee \& Kim (2014) & Yes & & Yes & & Yes & \\
\hline Bazan et al. (2014) & Yes & & & Yes & & \\
\hline Hammami et al. (2015) & Yes & & & & & Yes \\
\hline Yu \& Hsu (2016) & Yes & & Yes & & & \\
\hline Sarkar et al. (2016a) & & Yes & & & & Yes \\
\hline Sarkar et al. (2016b) & & Yes & Yes & & & Yes \\
\hline Sarkar et al. (2017) & Yes & & & Yes & & \\
\hline Wangsa (2017) & Yes & & & & & Yes \\
\hline Hariga et al. (2017) & Yes & & & & & Yes \\
\hline Sarkar et al. (2018) & & Yes & & & & Yes \\
\hline Daryanto \& Wee (2018) & Yes & & & & Yes & Yes \\
\hline Tiwari et al. (2018) & Yes & & Yes & & Yes & Yes \\
\hline Bai et al. (2019) & Yes & & & & Yes & Yes \\
\hline Daryanto et al. (2019a) & & Yes & & & Yes & Yes \\
\hline Daryanto et al. (2019b) & Yes & & Yes & Yes & Yes & Yes \\
\hline Marchi et al. (2019) & Yes & & Yes & & & Yes \\
\hline This paper & & Yes & & Yes & Yes & Yes \\
\hline
\end{tabular}

\section{MODEL DEVELOPMENT}

This model begins with the following scenario. Suppose a supply chain consisting of a manufacturer, a 3PL, and a buyer. The 3PL company supports the buyer's logistics activities by ordering, holding, and then delivering the items periodically. The manufacturer starts the production based on the 3PL's order $\left(Q_{l}\right)$. The manufacturer's production is imperfect and produces a certain rate of defective products with a known probability $(\beta)$. The manufacturer carries out a quality inspection to prevent the delivery of defective products. The 3PL performs the transportation of $Q_{l}$ from the manufacturer in one shipment. Then, the 3PL delivers the products to the buyer, $n$ times per cycle $(T)$ in a constant quantity $\left(Q_{2}\right)$, and constant time interval $\left(T_{d}\right)$. The supply chain member works together to minimize the negative impacts of their activities as well as their total cost. The study considers the following assumptions:

(1) A single type of product is considered in which the demand rate $(D)$ is known and constant,

(2) The manufacturer's production rate $(R)$ is known, constant, and larger than the demand rate,

(3) The deterioration rate $(\theta)$ of the inventory is constant per unit time,

(4) The deteriorated items will be disposed at the end of the cycle,

(5) The 3PL performs all the transportation by truck,
(6) The defective products will be stored until the end of the production period and then be sold to a secondary market,

(7) Demand shortage is not allowed. follows:

Other notations used in the proposed model are as

$T C_{m}, T C_{p}, \quad$ The total cost of the manufacturer, 3PL, and

$T C_{b} \quad$ buyer respectively (\$)

$I_{m}(t), I_{p}(t)$, On hand inventory of the supply chain

$I_{b}(t) \quad$ members at time $t$ (manufacturer, 3PL, and buyer respectively) (units)

Q $0 \quad$ Manufacturer's production quantity per cycle (units)

$T_{p} \quad$ Manufacturer's production period (year)

$s_{m} \quad$ Setup cost (\$/cycle)

$p_{m} \quad$ Production cost (\$/unit)

$P_{e} \quad$ Carbon emissions from production activities (tonCO 2 /unit)

$q_{m} \quad$ Quality inspection cost (\$/unit)

$o_{p}, o_{b} \quad$ Ordering cost of the 3PL and buyer respectively (\$/cycle)

$h_{m}, h_{p}, h_{b} \quad$ Holding cost of the supply chain members (\$/unit/year)

$d_{c m}, \quad d_{c p}, \quad$ Deterioration cost of the supply chain

$d_{c b} \quad$ members (\$/unit)

$W_{e m}, W_{e p}$, Energy consumption from the inventory

$W_{e b} \quad$ holding of the supply chain members (kWh/unit/year) 


\begin{tabular}{|c|c|}
\hline $\begin{array}{l}D_{e m}, \quad D_{e p}, \\
D_{e b}\end{array}$ & $\begin{array}{l}\text { The supply chain members' emission from } \\
\text { waste disposal (tonCO } \mathrm{CO}_{2} \text { unit) }\end{array}$ \\
\hline$f_{l}$ & $\begin{array}{l}\text { Fixed transportation cost per delivery of } Q_{1} \\
\text { (\$/delivery) }\end{array}$ \\
\hline$c_{1}$ & $\begin{array}{l}\text { Fuel consumption of an empty truck to } \\
\text { deliver } Q_{l}(\text { liter } / \mathrm{km})\end{array}$ \\
\hline$c_{1 a}$ & $\begin{array}{l}\text { Fuel consumption per ton of } Q_{1} \\
\text { (liter/km/ton) }\end{array}$ \\
\hline$d_{1}$ & Distance from manufacturer to 3PL (km) \\
\hline$f_{2}$ & $\begin{array}{l}\text { Fixed transportation cost per delivery of } Q_{2} \\
\text { (\$/delivery) }\end{array}$ \\
\hline$c_{2}$ & $\begin{array}{l}\text { Fuel consumption of an empty truck to } \\
\text { deliver } Q_{2}(\text { liter } / \mathrm{km})\end{array}$ \\
\hline$c 2 a$ & $\begin{array}{l}\text { Fuel consumption per ton of } Q_{2} \\
\text { (liter/km/ton) }\end{array}$ \\
\hline$d_{2}$ & Distance from 3PL to the buyer $(\mathrm{km})$ \\
\hline$v_{c}$ & Fuel price $(\$ /$ liter $)$ \\
\hline$b$ & Product weight $(\mathrm{kg})$ \\
\hline$E[\beta]$ & $\begin{array}{l}\text { The expected value of defective products } \\
\text { probability }\end{array}$ \\
\hline $\mathrm{Ee}$ & $\begin{array}{l}\text { Emission from electricity consumption } \\
\text { (tonCO } / \mathrm{kWh})\end{array}$ \\
\hline $\mathrm{Fe}$ & $\begin{array}{l}\text { Emission from vehicle's fuel consumption } \\
\text { (tonCO } 2 / \text { liter) }\end{array}$ \\
\hline$T x$ & Carbon tax rate $(\$ /$ tonCO 2$)$ \\
\hline$n$ & 3PL's delivery frequencies per cycle \\
\hline$T_{d}$ & $\begin{array}{l}\text { Delivery cycle time from the 3PL to the } \\
\text { buyer (year); } T_{d}=T_{b}\end{array}$ \\
\hline
\end{tabular}

\section{1 $T C_{b}$ and $T E_{b}$ Development}

$$
T C_{b}=C_{O b}+C_{H b}+C_{D b}
$$

The $T C_{b}$ consists of the order receiving, inventory holding, and deterioration costs, respectively considering the emission.

$$
C_{O b}=\frac{o_{b}}{T_{b}}
$$

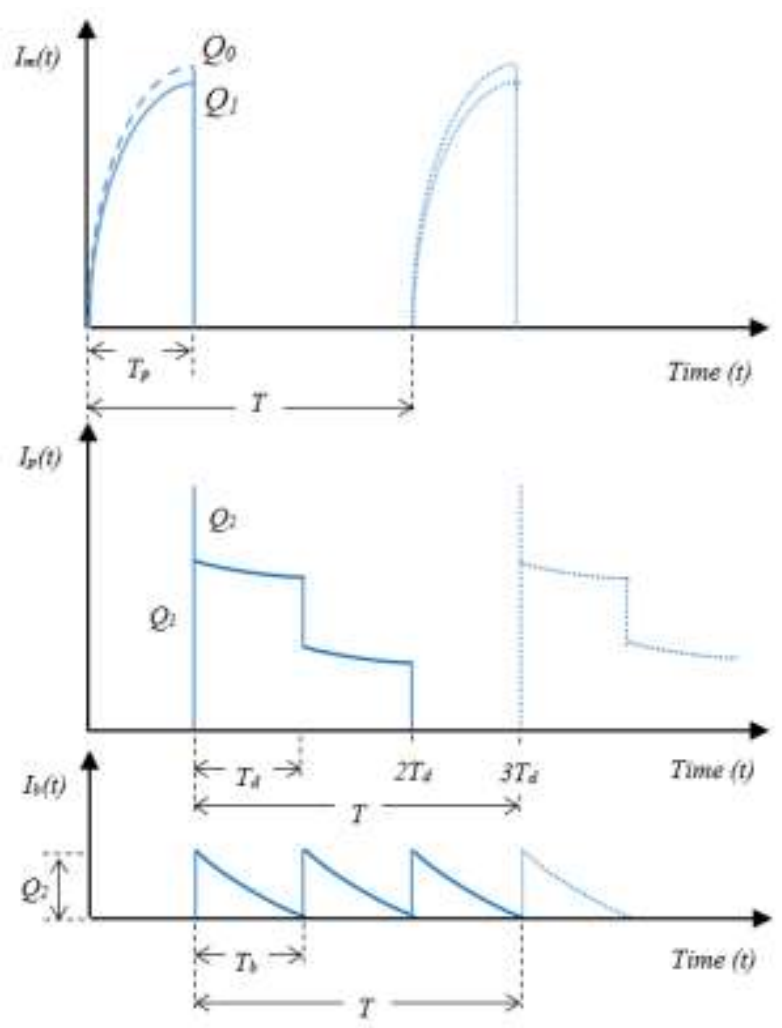

Figure 1 The manufacturer, 3PL, and buyer's inventory

From Figure 1, and for the boundary conditions $I_{b}(0)=Q_{2} ; I_{b}\left(T_{b}\right)=0$

$$
\begin{gathered}
I_{b}(t)=\frac{D}{\theta}\left(e^{\theta\left(T_{b}-t\right)}-1\right), \quad \text { for } 0 \leq t \leq T_{b} \\
Q_{2}=\frac{D}{\theta}\left(e^{\theta T_{b}}-1\right)
\end{gathered}
$$

Therefore,

$$
C_{H b}=\left(h_{b}+w_{e b} E_{e} T_{x}\right) \frac{1}{T_{b}}\left(\int_{0}^{T_{b}} I_{b}(t) d T\right)=\left(h_{b}+w_{e b} E_{e} T_{x}\right) \frac{1}{T_{b}}\left(\frac{D}{\theta^{2}} e^{\theta T_{b}}-\frac{D T_{b}}{\theta}-\frac{D}{\theta^{2}}\right)
$$

and

$$
C_{D b}=\left(d_{c b}+D_{e b} T_{x}\right) \frac{1}{T_{b}}\left(Q_{2}-D T_{b}\right)
$$

The total carbon emissions of the buyer are

$$
T E_{b}=\left(w_{e b} E_{e}\right) \frac{1}{T_{b}}\left(\frac{D}{\theta^{2}} e^{\theta T_{b}}-\frac{D T_{b}}{\theta}-\frac{D}{\theta^{2}}\right)+\left(D_{e b}\right) \frac{1}{T_{b}}\left(\frac{D}{\theta}\left(e^{\theta T_{b}}-1\right)-D T_{b}\right)
$$

\section{$3.2 T C_{p}$ and $T E_{p}$ Development}

$$
T C_{p}=C_{O p}+C_{T p}+C_{H p}+C_{D p}
$$

$T C_{p}$ consists of the ordering, transportation, inventory holding, and deterioration costs, respectively considering the emission. For a single order per cycle,

$$
C_{O p}=\frac{o_{p}}{n T_{b}}
$$


The 3PL takes responsibility for transporting $Q_{1}$ from the manufacturer to the 3PL's warehouse and transporting $n Q_{2}$ from the 3PL's warehouse to the buyer. The transportation cost depends on the fixed cost per delivery, the variable cost of the load and carbon emissions cost from the truck (Bonney \& Jaber, 2011; Wahab et al., 2011).

Therefore,

$$
\begin{gathered}
C_{T p}=\frac{1}{n T_{b}}\left(f_{1}+\left(2 d_{1} c_{1} v_{c}+d_{1} c_{1 a} b Q_{1} v_{c}\right)+\left(2 d_{1} c_{1} F_{e} T_{x}+d_{1} c_{1 a} b Q_{1} F_{e} T_{x}\right)\right) \\
+\frac{1}{T_{b}}\left(f_{2}+\left(2 d_{2} c_{2} v_{c}+d_{2} c_{2 a} b Q_{2} v_{c}\right)+\left(2 d_{2} c_{2} F_{e} T_{x}+d_{2} c_{2 a} b Q_{2} F_{e} T_{x}\right)\right)
\end{gathered}
$$

From Figure 2, by implementing a cross docking, $I_{p}(0)=Q_{1}-Q_{2}$. Further, at $t=(n-1) T_{d}$, the 3PL's inventory = 0 .

Therefore,

$$
\begin{gathered}
I_{p}(0)=Q_{2}\left(e^{\theta T_{d}}+\ldots+\left(e^{\theta T_{d}}\right)^{n-1}\right)=Q_{2} e^{\theta T_{d}}\left(\frac{1-e^{(n-1)\left(\theta T_{d}\right)}}{1-e^{\theta T_{d}}}\right) \\
Q_{1}=I_{p}(0)+Q_{2}=Q_{2} e^{\theta T_{d}}\left(\frac{1-e^{(n-1)\left(\theta T_{d}\right)}}{1-e^{\theta T_{d}}}\right)+Q_{2}
\end{gathered}
$$

$$
Q_{1}=\frac{D}{\theta}\left(e^{\theta T_{b} n}-1\right)
$$

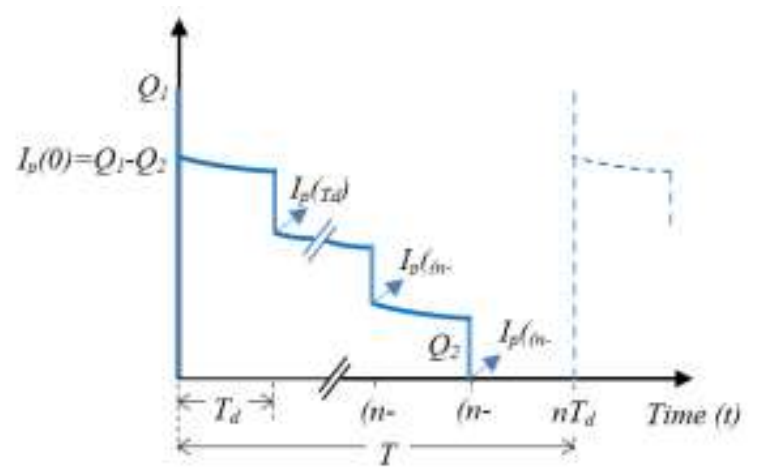

Figure 2 The 3PL's inventory level (Daryanto et al., 2019a)

The $C_{D p}$ can be derived as

$$
C_{D p}=\frac{\left(d_{c p}+D_{e p} T_{x}\right)}{n T_{b}}\left(\frac{D}{\theta}\left(e^{\theta T_{b} n}-1\right)-n\left(\frac{D}{\theta}\left(e^{\theta T_{b}}-1\right)\right)\right)
$$

and

$$
C_{H p}=\frac{\left(h_{p}+w_{e p} E_{e} T_{x}\right)}{n T_{b}} \frac{\left(\frac{D}{\theta}\left(e^{\theta T_{b} n}-1\right)-n\left(\frac{D}{\theta}\left(e^{\theta T_{b}}-1\right)\right)\right)}{\theta}
$$

The total carbon emissions of the 3PL are

$$
\begin{aligned}
T E_{p}=\frac{1}{T}\left(2 d_{1} c_{1} F_{e}\right. & \left.+d_{1} c_{1 a} b Q_{1} F_{e}\right)+\frac{1}{T_{b}}\left(2 d_{2} c_{2} F_{e}+d_{2} c_{2 a} b Q_{2} F_{e}\right) \\
& +\frac{w_{e p} E_{e}}{n T_{b}} \frac{\left(\frac{D}{\theta}\left(e^{\theta T_{b} n}-1\right)-n\left(\frac{D}{\theta}\left(e^{\theta T_{b}}-1\right)\right)\right)}{\theta} \\
& +\frac{D_{e p}}{n T_{b}}\left(\frac{D}{\theta}\left(e^{\theta T_{b} n}-1\right)-n\left(\frac{D}{\theta}\left(e^{\theta T_{b}}-1\right)\right)\right)
\end{aligned}
$$

\section{3 $T C_{m}$ and $T E_{m}$ Development}

$$
T C_{m}=C_{S m}+C_{P m}+C_{Q m}+C_{H m}+C_{D m}
$$

$T C_{m}$ consists of the setup, production, quality inspection, inventory holding, and deterioration costs, respectively, considering the emission. For a single setup per cycle, 


$$
\begin{gathered}
C_{S m}=\frac{s_{m}}{n T_{b}} \\
C_{P m}=\frac{1}{n T_{b}}\left(p_{m}+P_{e} T_{x}\right) T_{p} R
\end{gathered}
$$

The emission from production activity is a function of its production rate (Bazan et al., 2017; Aljazzar et al., 2018) and has the following equation $P_{e}=a_{p} R^{2}-b_{p} R+c_{p}$ where $a_{p}$, $b_{p}$, and $c_{p}$ are emissions parameters.
For a $100 \%$ quality inspection,

$$
C_{Q m}=\frac{1}{n T_{b}} q_{m} T_{p} R
$$

Due to the imperfect production system, the effective production rate of the manufacturer becomes $(1-E[\beta]) R$. From Figure 1, and for the boundary conditions $I_{m}(0)=$ $0 ; I_{m}\left(T_{p}\right)=Q_{1}$

$$
\begin{gathered}
I_{m}(t)=\frac{(1-E[\beta]) R}{\theta}\left(1-e^{-\theta t}\right), \text { for } 0 \leq t \leq T_{p} \\
I_{m}\left(T_{p}\right)=Q_{1}=\frac{(1-E[\beta]) R}{\theta}\left(1-e^{-\theta T_{p}}\right)
\end{gathered}
$$

Besides, for defective products

$$
I_{m d}(t)=\frac{E[\beta] R}{\theta}\left(1-e^{-\theta t}\right), \text { for } 0 \leq t \leq T_{p}
$$

Therefore, the expected inventory cost for both the good and defective products per unit time is

$$
\begin{gathered}
C_{H m}=\frac{\left(h_{m}+w_{e m} E_{e} T_{x}\right)}{T}\left(\int_{0}^{T_{p}} I_{m}(t) d t+\int_{0}^{T_{p}} I_{m d}(t) d t\right) \\
=\frac{\left(h_{m}+w_{e m} E_{e} T_{x}\right)}{n T_{b}}\left(\frac{(1-E[\beta]) R}{\theta^{2}}\left(\theta T_{p}+e^{-\theta T_{p}}-1\right)+\frac{E[\beta] R}{\theta^{2}}\left(\theta T_{p}+e^{-\theta T_{p}}-1\right)\right)
\end{gathered}
$$

The deterioration cost per year is

$$
C_{D m}=\frac{\left(d_{c m}+D_{e m} T_{x}\right)}{T}\left(\left((1-E[\beta]) R T_{p}-Q_{1}\right)+\left(E[\beta] R T_{p}-\frac{E[\beta] R}{\theta}\left(1-e^{\theta T_{p}}\right)\right)\right)
$$

From Eq. (11) and (19),

$$
T_{p}=-\frac{\ln \left(\frac{D+(1-E[\beta]) R-D e^{\theta T_{b} n}}{(1-E[\beta]) R}\right)}{\theta}
$$

The expected total carbon emissions of the manufacturer are

$$
\begin{aligned}
T E_{m}= & \frac{w_{e m} E_{e}}{T}\left(\frac{(1-E[\beta]) R}{\theta^{2}}\left(\theta T_{p}+e^{-\theta T_{p}}-1\right)+\frac{E[\beta] R}{\theta} T_{p}+\frac{E[\beta] R}{\theta^{2}}\left(e^{-\theta T_{p}}-1\right)\right) \\
& +\frac{D_{e m}}{T}\left(\left((1-E[\beta]) R T_{p}-Q_{1}\right)+\left(E[\beta] R T_{p}-\frac{E[\beta] R}{\theta}\left(1-e^{\theta T_{p}}\right)\right)\right)+\frac{P_{e}}{T} T_{p} R
\end{aligned}
$$

\subsection{Solution Procedure}

The total cost of the supply chain for an integrated decision is

$$
T C=T C_{b}+T C_{p}+T C_{m}
$$

The convexity of the cost function in $n$ and $T_{b}$ is proved empirically using the illustrative data in section 4 , as shown in Figure 3. 


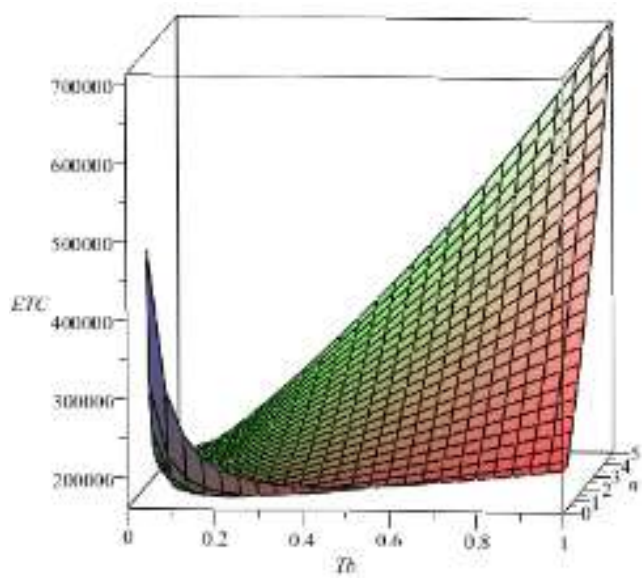

Figure 3 Convexity of ETC function in $n$ and $T_{b}$

A solution procedure is developed to determine the optimal $n$ and $T_{b}$ that will minimize the above total cost, adapted from Wang et al. (2011) and Daryanto et al. (2019a), as follows:

Step 1. Substitute Eq. (23) into TC.

Step 2. Set $n=1$. Input $n$ and other parameters into TC. Step 3. Derive the partial derivative of TC with respect to $T_{b}$ and set it equal to zero.

Step 4. Solve the equation to find $T_{b}$.

Step 5. Use the available $n$ and $T_{b}$ to calculate $T C\left(n, T_{b}\right)$. Step 6. Check for minimal TC.

If $T C\left(n, T_{b}\right)<T C\left((n-1), T_{b}(n-1)\right)$, repeat Step 3 with new $n=$ $n+1$, otherwise go to Step 7 .

Step 7. Define $n-1$ as $n^{*}$ (optimal n). From Eq. (23), (11) and (4) derive the optimal $T_{p}, Q_{1}$, and $Q_{2}$. Calculate $Q_{0}=$ $T_{p} R$.

\section{ILLUSTRATIVE EXAMPLE AND DISCUSSION}

For illustration, a numerical example is presented. Suppose a supply chain of corrugated box product among one packaging manufacturer, a 3PL company, and one consumer goods manufacturer as the buyer, with the following data adapted from Wang et al. (2011), Jaber et al. (2013), and Hariga et al. (2017).

$$
\begin{array}{ll}
\theta & =0.1 \\
E[\beta] & =0.01 \\
b & =4 \mathrm{~kg} \\
T x & =\$ 61.8 / / \text { tonCO }_{2} \\
F_{e} & =2.6 \times 10^{-3} \text { tonCO }_{2} / \text { liter } \\
E_{e} & =0.5 \times 10^{-3} \text { tonCO } / \mathrm{kWh} \\
D & =10,000 \text { units/year } \\
o_{b} & =\$ 300 / \text { cycle } \\
h_{b} & =\$ 3 / \text { unit/year } \\
d_{c b} & =\$ 200 / \text { unit }
\end{array}
$$

$$
\begin{aligned}
& D_{e b} \quad=1.2 \times 10^{-3} \text { tonCO } 2 / \text { unit } \\
& w_{e b} \quad=14.4 \mathrm{kWh} / \text { unit/year } \\
& o_{p} \quad=\$ 600 / \text { cycle } \\
& h_{p} \quad=\$ 1.5 / \text { unit } / \text { year } \\
& d_{c p} \quad=\$ 100 / \text { unit } \\
& D_{e p} \quad=1.2 \times 10^{-3} \text { tonCO } \mathrm{CO}_{2} / \text { unit } \\
& f_{1}=\$ 200 / \text { delivery } \\
& c_{1}=30 \text { liter } / 100 \mathrm{~km} \\
& c_{l a}=0.5 \text { liter } / 100 \mathrm{~km} / \mathrm{ton} \\
& d_{l} \quad=500 \mathrm{~km} \\
& f_{2}=\$ 100 / \text { delivery } \\
& c_{2}=25 \text { liter } / 100 \mathrm{~km} \\
& c_{2 a}=0.36 \text { liter } / 100 \mathrm{~km} / \mathrm{ton} \\
& d_{2} \quad=25 \mathrm{~km} \\
& v_{c} \quad=\$ 0.75 / \text { liter } \\
& w_{e p}=14.4 \mathrm{kWh} / \text { unit/year } \\
& R \quad=20,000 \text { units/year, } \\
& s_{m} \quad=\$ 2,000 / \text { cycle } \\
& p_{m} \quad=\$ 10 / \text { unit } \\
& q_{m} \quad=\$ 0.1 / \text { unit } \\
& h_{m} \quad=\$ 0.5 / \text { unit/year } \\
& d_{c m} \quad=\$ 30 / \text { unit } \\
& D_{e m}=1.2 \times 10^{-3} \text { tonCO } 2 \text { /unit } \\
& w_{e m}=14.4 \mathrm{kWh} / \text { unit } / \text { year } \\
& a_{p} \quad=0.12 \times 10^{-9} \text { tonCO }_{2} \text {. year }{ }^{2} / \text { unit }^{3} \\
& b_{p} \quad=1.2 \times 10^{-6} \text { tonCO } 2 \text { year/ unit }{ }^{2} \\
& c_{p} \quad=1.4 \times 10^{-3} \text { tonCO } 2 / \text { unit }
\end{aligned}
$$

\begin{tabular}{|c|c|c|c|c|c|c|c|c|c|}
\hline$n$ & $T_{b}=T_{d}$ & $T_{p}$ & $Q_{0}$ & $Q_{1}$ & $Q_{2}$ & $T C_{m}$ & $T C_{p}$ & $T C_{b}$ & $T C$ \\
\hline 1 & 0.1588 & 0.0812 & $1,623.9$ & $1,601.2$ & $1,601.2$ & $133,526.7$ & $7,552.4$ & $20,614.3$ & $161,693.5$ \\
\hline $2^{*}$ & 0.0944 & 0.0968 & $1,935.7$ & $1,907.1$ & 949.1 & $132,113.3$ & $12,653.9$ & $14,287.5$ & $159,054.7^{*}$ \\
\hline 3 & 0.0693 & 0.1067 & $2,133.5$ & $2,100.9$ & 695.5 & $131,521.0$ & $15,224.6$ & $12,474.5$ & $159,220.1$ \\
\hline 4 & 0.0557 & 0.1145 & $2,290.3$ & $2,254.5$ & 558.9 & $131,170.4$ & $16,993.8$ & $11,930.0$ & $160,094.1$ \\
\hline 5 & 0.0472 & 0.1213 & $2,426.3$ & $2,387.6$ & 473.0 & $130,934.3$ & $18,391.9$ & $11,899.5$ & $161,225.8$ \\
\hline 6 & 0.0413 & 0.1275 & $2,549.4$ & $2,507.9$ & 413.7 & $130,766.3$ & $19,581.8$ & $12,114.3$ & $162,462.4$ \\
\hline
\end{tabular}

Maple 15 software was used to perform the derivation and calculation following the proposed solution procedure. It was conducted on a PC with AMD $3.20 \mathrm{GHz}$ processor and 4 GB RAM. Solving the above problem using the proposed solution procedure, results in an optimal value of $n$ as $n^{*}=2$ with $T_{b} *=0.0944$ and $T C^{*}=\$ 159,054.7$. From Eq. (23), (11), and (4) the production period $\left(T_{p}\right)$, manufacturer's production quantity $\left(Q_{0}\right)$, delivery size from the manufacturer $\left(Q_{1}\right)$, and delivery size from the 3PL $\left(Q_{2}\right)$ are 0.0968 years, 1,935.7 units, 1,907.1 units, and 949.1 units respectively. Therefore, the $n Q_{2} *<Q_{1}^{*}<Q_{0}^{*}$ due to deterioration. The complete results are provided in Table 2. Further, from Eq. (7), (14), and (24) the expected total emissions (TE) from the supply chain are 275.58 ton $\mathrm{CO}_{2} /$ year.

Table 2 also shows that the manufacturer's total cost decreases for more delivery frequencies per cycle. An opposite situation is faced by the 3PL while the buyer has the optimal $n^{*}=5$ with the lowest $T C_{b}=\$ 11,899.5 /$ year. If the decision is made solely by the retailer, the ETC is $\$ 161,225.8$ which is $1.35 \%$ higher than the ETC for $n^{*}$. The ETE is 278.71 tonCO $\mathrm{C}_{2}$ per year. These results show the advantage of supply chain integration in reducing total cost and carbon emissions. Table 3 presents the cost and emission of the manufacturer, 3PL, and buyer. In this example, emissions from production activities account for the largest share of the total supply chain emissions.

Table 3 Result of the illustrative example 
Table 4 Cost and emission of the manufacturer, 3PL, and buyer

\begin{tabular}{lll}
\hline & Cost (\$) & Emissions (tonCO 2$)$ \\
\hline Manufacturer & & \\
Setup & $10,586.5$ & \\
Production & $118,548.6$ & 260.26 \\
Inspection & $1,024.6$ & \\
Inventory holding & 467.1 & 3.56 \\
Deterioration & $1,486.5$ & 0.06 \\
Total & $132,113.3$ & 263.88 \\
\hline 3PL & & \\
Ordering & $3,176.0$ & \\
Transportation & $3,779.2$ & 4.74 \\
Inventory holding & 927.3 & 3.43 \\
Deterioration & $4,771.4$ & 0.06 \\
Total & $12,653.9$ & 8.23 \\
\hline Buyer & & \\
Ordering & $3,176.0$ & \\
Inventory holding & $1,632.2$ & 3.41 \\
Deterioration & $9,479.3$ & 0.06 \\
Total & $14,287.5$ & 3.47 \\
\hline Expected total cost $(T C)$ per year & $159,054.7$ & \\
Expected total emissions (TE) per year & & 275.58 \\
\hline
\end{tabular}

When the model does not consider carbon emissions costs, the optimal $n=2$ with $T_{b}=0.0959$. The $Q_{0}, Q_{1}$, and $Q_{2}$ are higher than the result for the model with carbon emissions. Substituting these results into the model with carbon emissions cost, one has $T C=\$ 159,059.3$ and $T E=$
275.73 tonCO $\mathrm{CO}_{2} /$ year. These results are $0.003 \%$ and $0.056 \%$ higher than the result of the proposed model with carbon emissions. Table 4 provides a comparison of results with and without carbon emissions cost.

Table 5 Comparison of results with and without carbon emission cost

\begin{tabular}{|c|c|c|c|c|c|}
\hline & $\begin{array}{l}\text { Integrated decision } \\
\text { considering emissions } \\
\text { (a) }\end{array}$ & $\begin{array}{c}\text { Buyer's individual decision } \\
\text { with emissions } \\
\text { (b) }\end{array}$ & $\begin{array}{l}\text { Saving } \\
((b-a) / b) \\
\times 100 \%\end{array}$ & $\begin{array}{l}\text { Integrated decision } \\
\text { without emissions } \\
\text { (c) }\end{array}$ & $\begin{array}{c}\text { Saving } \\
((c-a) / c) x \\
100 \%\end{array}$ \\
\hline$n$ & 2 & 5 & - & 2 & - \\
\hline$T_{b}$ & 0.0944 & 0.0472 & - & 0.0959 & - \\
\hline TC & \$159,054.7/year & \$161,225.8/year & $1.35 \%$ & \$159,059.3/year & $0.003 \%$ \\
\hline TE & 275.58 ton $\mathrm{CO}_{2} /$ year & 278.71 ton $\mathrm{CO}_{2} /$ year & $1.12 \%$ & 275.73 ton $\mathrm{CO}_{2} /$ year & $0.056 \%$ \\
\hline
\end{tabular}

A sensitivity analysis was performed by changing the value of one parameter by $\pm 10 \%$ and $\pm 20 \%$, as presented in Table 5. The percentage change in expected total cost is calculated as follow:

$$
\% C T C=\frac{T C-T C^{*}}{T C^{*}} \times 100 \%
$$

The following insights can be identified from the above study:

(1) For all parameters, when the values increase, the total cost also increases. However, the rates on how the \% CTC increase vary.

(2) The change in demand rate $(D)$ and production cost $\left(p_{m}\right)$ have a significant influence on the total cost. The increase in these parameters results in an increase in the total cost for more than $50 \%$ of the parameter's value increase. The result provides a supply chain manager or decision-maker managerial insights to carefully control the production cost to reduce the total cost.

(3) The total cost is also sensitive to the changes in production rate $(R)$, carbon emission tax $\left(T_{x}\right)$, deterioration rate $(\theta)$, setup and ordering cost $\left(s_{m}, o_{p}\right.$, $\left.o_{b}\right)$, and deterioration cost $\left(d_{c m}, d_{c p}, d_{c b}\right)$. These results mean that the setup cost, the ordering cost, and the deterioration cost reduction are also significant in reducing the total cost. The manager needs to monitor the production rate to synchronize with the demand rate, thus keeping the inventory level as low as possible. Investing in preservation technology to reduce the deterioration rate is another option to decrease the cost.

(4) The change in the expected value of defective products probability $(E[\beta])$, quality inspection cost $\left(q_{m}\right)$, fixed transportation cost $\left(f_{1}, f_{2}\right)$, fuel price $\left(v_{c}\right)$, holding cost $\left(h_{m}, h_{p}, h_{b}\right)$, the fuel consumption of an empty truck $\left(c_{1}\right.$, $\left.c_{2}\right)$, and delivery distance $\left(d_{1}, d_{2}\right)$ are less significant.

(5) The change in the fuel consumption per ton payload $\left(c_{1 a}, c_{2 a}\right)$, product weight $(b)$, and warehouse energy consumption $\left(w_{e m}, w_{e p}, w_{e b}\right)$ are not significant as well. An increase of $20 \%$ from these parameters only increase the \%CTC by less than $0.1 \%$ 
Table 6 Sensitivity analysis of different parameters

\begin{tabular}{|c|c|c|c|c|c|c|c|c|}
\hline Parameter & Change & $n^{*}$ & $T_{b}$ & $T_{p}$ & $Q_{1}$ & $Q_{2}$ & $T C$ & $\%$ CTC \\
\hline \multirow{5}{*}{$D$} & $-20 \%$ & 2 & 0.1069 & 0.0877 & $1,728.4$ & 859.6 & $130,680.9$ & -21.7 \\
\hline & $-10 \%$ & 2 & 0.1002 & 0.0924 & $1,821.1$ & 906.0 & $144,915.0$ & -9.76 \\
\hline & $\{8000\}$ & 2 & 0.0944 & 0.0968 & $1,907.1$ & 949.1 & $159,054.7$ & 0 \\
\hline & $+10 \%$ & 2 & 0.0895 & 0.1009 & $1,987.4$ & 989.3 & $173,115.2$ & 8.12 \\
\hline & $+20 \%$ & 2 & 0.0852 & 0.1047 & $2,062.8$ & $1,027.0$ & $187,108.6$ & 15.0 \\
\hline \multirow{5}{*}{$R$} & $-20 \%$ & 2 & 0.0933 & 0.1196 & $1,882.8$ & 937.0 & $151,776.5$ & -4.79 \\
\hline & $-10 \%$ & 2 & 0.0939 & 0.1070 & $1,896.6$ & 943.9 & $155,079.6$ & -2.56 \\
\hline & $\{20000\}$ & 2 & 0.0944 & 0.0968 & $1,907.1$ & 949.1 & $159,054.7$ & 0 \\
\hline & $+10 \%$ & 2 & 0.0948 & 0.0883 & $1,915.1$ & 953.0 & $163,684.0$ & 2.83 \\
\hline & $+20 \%$ & 2 & 0.0951 & 0.0812 & $1,921.1$ & 956.0 & $168,955.4$ & 5.86 \\
\hline \multirow{5}{*}{$\theta$} & $-20 \%$ & 2 & 0.1038 & 0.1062 & $2,093.5$ & $1,042.4$ & $155,372.6$ & -2.37 \\
\hline & $-10 \%$ & 2 & 0.0988 & 0.1011 & $1,993.8$ & 992,5 & $157,255.9$ & -1.14 \\
\hline & $\{0.1\}$ & 2 & 0.0944 & 0.0968 & $1,907.1$ & 949.1 & $159,054.7$ & 0 \\
\hline & $+10 \%$ & 2 & 0.0906 & 0.0929 & $1,830.9$ & 910.9 & $160,778.6$ & 1.07 \\
\hline & $+20 \%$ & 2 & 0.0872 & 0.0895 & $1,763.2$ & 877.0 & $162,436.6$ & 2.08 \\
\hline \multirow{5}{*}{$S_{m}, o_{p}, o_{b}$} & $-20 \%$ & 2 & 0.0864 & 0.0884 & $1,743.2$ & 867.8 & $155,516.1$ & -2.27 \\
\hline & $-10 \%$ & 2 & 0.0905 & 0.0927 & $1,827.0$ & 909.4 & $157,324.4$ & -1.10 \\
\hline & $\{2000,600,300\}$ & 2 & 0.0944 & 0.0968 & $1,907.1$ & 949.1 & $159,054.7$ & 0 \\
\hline & $+10 \%$ & 2 & 0.0982 & 0.1007 & $1,984.0$ & 987.1 & $160,715.2$ & 1.03 \\
\hline & $+20 \%$ & 2 & 0.1019 & 0.1045 & $2,058.1$ & $1,023.8$ & $162,314.7$ & 2.01 \\
\hline \multirow{5}{*}{$p_{m}$} & $-20 \%$ & 2 & 0.0951 & 0.0975 & $1,920.9$ & 955.9 & $138,560.5$ & -14.8 \\
\hline & $-10 \%$ & 2 & 0.0948 & 0.0971 & $1,914.0$ & 952.5 & $148,807.8$ & -6.88 \\
\hline & $\{10\}$ & 2 & 0.0944 & 0.0968 & $1,907.1$ & 949.1 & $159,054.7$ & 0 \\
\hline & $+10 \%$ & 2 & 0.0941 & 0.0964 & $1,900.4$ & 945.7 & $169,300.7$ & 6.05 \\
\hline & $+20 \%$ & 2 & 0.0938 & 0.0961 & $1,893.6$ & 942.4 & $179,546.4$ & 11.4 \\
\hline \multirow{5}{*}{$E[\beta]$} & $-20 \%$ & 2 & 0.0945 & 0.0966 & $1,907.7$ & 949.4 & $158,804.5$ & -0.16 \\
\hline & $-10 \%$ & 2 & 0.0945 & 0.0967 & $1,907.4$ & 949.2 & $158,929.4$ & -0.08 \\
\hline & $\{0.01\}$ & 2 & 0.0944 & 0.0968 & $1,907.1$ & 949.1 & $159,054.7$ & 0 \\
\hline & $+10 \%$ & 2 & 0.0944 & 0.0969 & $1,906.8$ & 948.9 & $159,180.3$ & 0.08 \\
\hline & $+20 \%$ & 2 & 0.0944 & 0.0970 & $1,906.5$ & 948.8 & $159,305.5$ & 0.16 \\
\hline \multirow{5}{*}{$q_{m}$} & $-20 \%$ & 2 & 0.0945 & 0.0968 & $1,907.3$ & 949.1 & $158,849.3$ & -0.13 \\
\hline & $-10 \%$ & 2 & 0.0945 & 0.0968 & $1,907.2$ & 949.1 & $158,952.3$ & -0.06 \\
\hline & $\{0.1\}$ & 2 & 0.0944 & 0.0968 & $1,907.1$ & 949.1 & $159,054.7$ & 0 \\
\hline & $+10 \%$ & 2 & 0.0944 & 0.0968 & $1,907.1$ & 949.0 & $159,157.1$ & 0.06 \\
\hline & $+20 \%$ & 2 & 0.0944 & 0.0968 & $1,907.0$ & 949.0 & $159,259.5$ & 0.13 \\
\hline
\end{tabular}


Table 7 Sensitivity analysis of different parameters (cont')

\begin{tabular}{|c|c|c|c|c|c|c|c|c|}
\hline Parameter & Change & $n^{*}$ & $T_{b}$ & $T_{p}$ & $Q_{1}$ & $Q_{2}$ & $T C$ & $\%$ CTC \\
\hline & $-20 \%$ & 2 & 0.0935 & 0.0958 & $1,887.4$ & 939.3 & $158,628.9$ & $\begin{array}{l}-0.27 \\
\end{array}$ \\
\hline & $-10 \%$ & 2 & 0.0940 & 0.0963 & $1,897.3$ & 944.2 & $158,842.3$ & -0.13 \\
\hline \multirow[t]{5}{*}{$f_{1}, f_{2}$} & $\{200,100\}$ & 2 & 0.0944 & 0.0968 & $1,907.1$ & 949.1 & $159,054.7$ & 0 \\
\hline & $+10 \%$ & 2 & 0.0949 & 0.0973 & $1,916.9$ & 953.9 & $159,265.9$ & 0.13 \\
\hline & $+20 \%$ & 2 & 0.0954 & 0.0978 & $1,926.7$ & 958.7 & $159,476.0$ & 0.26 \\
\hline & $-20 \%$ & 2 & 0.0939 & 0.0962 & $1,895.2$ & 943.1 & $158,780.0$ & -0.17 \\
\hline & $-10 \%$ & 2 & 0.0942 & 0.0965 & $1,901.2$ & 946.1 & $158,917.5$ & -0.09 \\
\hline \multirow[t]{5}{*}{$v_{c}$} & $\{0.75\}$ & 2 & 0.0944 & 0.0968 & $1,907.1$ & 949.1 & $159,054.7$ & 0 \\
\hline & $+10 \%$ & 2 & 0.0947 & 0.0971 & $1,913.1$ & 952.0 & $159,191.3$ & 0.08 \\
\hline & $+20 \%$ & 2 & 0.0950 & 0.0974 & $1,919.0$ & 955.0 & $159,327.7$ & 0.17 \\
\hline & $-20 \%$ & 2 & 0.0956 & 0.0979 & $1,929.8$ & 960.3 & $158,575.0$ & -0.30 \\
\hline & $-10 \%$ & 2 & 0.0950 & 0.0973 & $1,918.4$ & 954.6 & $158,815.7$ & -0.15 \\
\hline \multirow[t]{5}{*}{$h_{m}, h_{p}, h_{b}$} & $\{0.5,1.5,3\}$ & 2 & 0.0944 & 0.0968 & $1,907.1$ & 949.1 & $159,054.7$ & 0 \\
\hline & $+10 \%$ & 2 & 0.0939 & 0.0962 & $1,896.1$ & 943.6 & $159,292.3$ & 0.15 \\
\hline & $+20 \%$ & 2 & 0.0934 & 0.0957 & $1,885.3$ & 938.2 & $159,528.6$ & 0.30 \\
\hline & $-20 \%$ & 2 & 0.1026 & 0.1053 & $2,073.3$ & $1,031.3$ & $155,778.3$ & -2.10 \\
\hline & $-10 \%$ & 2 & 0.0983 & 0.1007 & $1,985.0$ & 987.6 & $157,450.5$ & -1.02 \\
\hline \multirow[t]{5}{*}{$d_{c m}, d_{c p}, d_{c b}$} & $\{30,100,200\}$ & 2 & 0.0944 & 0.0968 & $1,907.1$ & 949.1 & $159,054.7$ & 0 \\
\hline & $+10 \%$ & 2 & 0.0910 & 0.0932 & $1,837.8$ & 914.7 & $160,598.2$ & 0.96 \\
\hline & $+20 \%$ & 2 & 0.0880 & 0.0901 & $1,775.4$ & 883.8 & $162,087$. & 1.877 \\
\hline & $-20 \%$ & 2 & 0.0937 & 0.0960 & $1,892.6$ & 941.8 & $158,740.0$ & -0.20 \\
\hline & $-10 \%$ & 2 & 0.0941 & 0.0964 & $1,899.9$ & 945.5 & $158,897.5$ & -0.10 \\
\hline \multirow[t]{5}{*}{$\mathrm{C}_{1}, \mathrm{C}_{2}$} & $\{0.30,0.25\}$ & 2 & 0.0944 & 0.0968 & $1,907.1$ & 949.1 & $159,054.7$ & 0 \\
\hline & $+10 \%$ & 2 & 0.0948 & 0.0971 & $1,914.4$ & 952.6 & $159,210.9$ & 0.10 \\
\hline & $+20 \%$ & 2 & 0.0952 & 0.0975 & $1,921.6$ & 956.2 & $159,366.9$ & 0.19 \\
\hline & $-20 \%$ & 2 & 0.0945 & 0.0968 & $1,907.1$ & 949.1 & $159,035.7$ & -0.012 \\
\hline & $-10 \%$ & 2 & 0.0944 & 0.0968 & $1,907.1$ & 949.1 & $159,045.0$ & -0.006 \\
\hline \multirow[t]{5}{*}{$\mathrm{C}_{1 a}, \mathrm{C}_{2 a}$} & $\{0.005,0.0036\}$ & 2 & 0.0944 & 0.0968 & $1,907.1$ & 949.1 & $159,054.7$ & 0 \\
\hline & $+10 \%$ & 2 & 0.0944 & 0.0968 & $1,907.1$ & 949.1 & $159,064.2$ & 0.006 \\
\hline & $+20 \%$ & 2 & 0.0944 & 0.0968 & $1,907.1$ & 949.1 & $159,073.6$ & 0.012 \\
\hline & $-20 \%$ & 2 & 0.0937 & 0.0960 & $1,892.6$ & 941.9 & $158,721.2$ & -0.21 \\
\hline & $-10 \%$ & 2 & 0.0941 & 0.0964 & $1,899.9$ & 945.5 & $158,888.1$ & -0.10 \\
\hline \multirow[t]{3}{*}{$d_{1}, d_{2}$} & $\{500,25\}$ & 2 & 0.0944 & 0.0968 & $1,907.1$ & 949.1 & $159,054.7$ & 0 \\
\hline & $+10 \%$ & 2 & 0.0948 & 0.0971 & $1,914.4$ & 952.6 & $159,220.7$ & 0.10 \\
\hline & $+20 \%$ & 2 & 0.0952 & 0.0975 & $1,921.6$ & 956.2 & $159,385.7$ & 0.21 \\
\hline
\end{tabular}




\begin{tabular}{|c|c|c|c|c|c|c|c|c|}
\hline Parameter & Change & $n^{*}$ & $T_{b}$ & $T_{p}$ & $Q_{1}$ & $Q_{2}$ & $T C$ & \%CTC \\
\hline \multirow{5}{*}{$T_{x}$} & $-20 \%$ & 2 & 0.0947 & 0.0971 & $1,912.9$ & 951.9 & $155,648.4$ & -2.19 \\
\hline & $-10 \%$ & 2 & 0.0946 & 0.0969 & $1,910.0$ & 950.5 & $157,351.6$ & -1.08 \\
\hline & $\{61.8\}$ & 2 & 0.0944 & 0.0968 & $1,907.1$ & 949.1 & $159,054.7$ & 0 \\
\hline & $+10 \%$ & 2 & 0.0943 & 0.0966 & $1,904.3$ & 947.7 & $160,757.7$ & 1.06 \\
\hline & $+20 \%$ & 2 & 0.0942 & 0.0965 & $1,901.5$ & 946.3 & $162,460.7$ & 2.10 \\
\hline \multirow{5}{*}{$\begin{array}{c}W_{e m}, W_{e p}, \\
W_{e b}\end{array}$} & $-20 \%$ & 2 & 0.0947 & 0.0971 & $1,913.2$ & 952.1 & $158,925.8$ & -0.08 \\
\hline & $-10 \%$ & 2 & 0.0946 & 0.0969 & $1,910.2$ & 950.6 & $158,990.3$ & -0.04 \\
\hline & $\{14.4\}$ & 2 & 0.0944 & 0.0968 & $1,907.1$ & 949.1 & $159,054.7$ & 0 \\
\hline & $+10 \%$ & 2 & 0.0943 & 0.0966 & $1,904.1$ & 947.6 & $159,118.7$ & 0.04 \\
\hline & $+20 \%$ & 2 & 0.0942 & 0.0965 & $1,901.1$ & 946.1 & $159,183.1$ & 0.08 \\
\hline \multirow{5}{*}{$b$} & $-20 \%$ & 2 & 0.0945 & 0.0968 & $1,907.1$ & 949.1 & $159,035.7$ & 0.012 \\
\hline & $-10 \%$ & 2 & 0.0944 & 0.0968 & $1,907.1$ & 949.1 & $159,045.0$ & 0.006 \\
\hline & $\{4\}$ & 2 & 0.0944 & 0.0968 & $1,907.1$ & 949.1 & $159,054.7$ & 0 \\
\hline & $+10 \%$ & 2 & 0.0944 & 0.0968 & $1,907.1$ & 949.1 & $159,064.2$ & 0.006 \\
\hline & $+20 \%$ & 2 & 0.0944 & 0.0968 & $1,907.1$ & 949.1 & $159,073.6$ & 0.012 \\
\hline
\end{tabular}

Note: $\{$.$\} Base value$

\section{CONCLUSION}

In this paper, we proposed an integrated three-echelon green supply chain inventory model considering carbon emissions for imperfect quality deteriorating items. The study considers emissions from production, transportation, warehousing, and waste disposal. A simple procedure was suggested to obtain a solution. This model enables the supply chain managers to optimize the number of deliveries per cycle, delivery interval, delivery quantity of the 3PL, and the lot size of the buyer simultaneously. It also determines the production quantity of the manufacturer and delivery quantity from the manufacturer to the 3PL. The example incorporates and reduces the total carbon emissions cost of the supply chain model. This study also shows the advantage of supply chain integration in reducing carbon emissions. The sensitivity analysis shows that the supply chain manager or decision-maker must give more attention to reducing the production cost, setup cost, ordering cost, and deteriorating cost.

One of the limitations of this study is the assumption of a deterministic demand without considering price-dependent demand or advertisement. However, in real situations, customer demand is probabilistic and is dependant on factors such as price and advertisement. Therefore, future research can consider stochastic demand as well as price and advertisement dependent demand. We can also extend the proposed model with a different carbon tariff system such as a carbon cap or a cap and trade system which have also been applied in several countries.

\section{ACKNOWLEDGEMENT}

The authors express their gratitude to the editor and anonymous reviewers for help to improve the quality of the paper. The draft copy of the paper was presented at the 6th
Annual Conference on Industrial and Systems Engineering (ACISE) 2019, Semarang, Indonesia. We want to express our thanks to the conference organizer for awarding our paper with the Best Paper Award.

\section{REFERENCES}

Alhaj, M.A., Svetinovic, D. and Diabat, A. (2016). A carbonsensitive two-echelon-inventory supply chain model with stochastic demand. Resources, Conservation and Recycling 108, pp. 82-87.

Aljazzar, S.M., Gurtu, A. and Jaber, M.Y. (2018). Delay-inpayments - A strategy to reduce carbon emissions from supply chains. Journal of Cleaner Production 170, pp. 636644.

Anderson, T., Liu, Z., Cruz, J. and Wang, J. (2020). Social and environmental sustainability: An empirical analysis of supply chain profitability and the recession. Operations and Supply Chain Management: An International Journal 13(2), pp. 176193.

Bai, Q., Gong, Y., Jin, M. and Xu, X. (2019). Effect of carbon emission reduction on supply chain coordination with vendormanaged deteriorating product inventory. International Journal of Production Economics 208, pp. 83-99.

Bazan, E., Jaber, M.Y. and Zanoni, S. (2015). Supply chain models with greenhouse gases emissions, energy usage and different coordination decisions. Applied Mathematical Modelling 39(17), pp. 5131-5151.

Bazan, E., Jaber, M.Y. and Zanoni, S. (2017). Carbon emissions and energy effects on a two-level manufacturer-retailer closed-loop supply chain model with remanufacturing subject to different coordination mechanisms. International Journal of Production Economics 183, pp. 394-408.

Bazan, E., Jaber, M.Y., Zanoni, S. and Zavanella, L.E. (2014). Vendor managed inventory (VMI) with consignment stock (CS) agreement for a two-level supply chain with an imperfect production process with/without restoration interruptions. International Journal of Production Economics 157, pp. 289-301. 
Benjaafar, S., Li, Y. and Daskin, M. (2013). Carbon footprint and the management of supply chains: Insights from simple models. IEEE Transactions on Automation Science and Engineering 10(1), pp. 99-116.

Bonney, M. and Jaber, M.Y. (2011). Environmentally responsible inventory models: Non-classical models for a non-classical era. International Journal of Production Economics 133(1), pp. 43-53.

Chen, X. and Hao, G. (2015). Sustainable pricing and production policies for two competing firms with carbon emissions tax. International Journal of Production Research 53(21), pp. 6408-6420.

Daryanto, Y. and Wee, H.M. (2018). Single vendor-buyer integrated inventory model for deteriorating items considering carbon emission. Proceeding of the 8th International Conference on Industrial Engineering and Operations Management, Bandung, Indonesia, pp. 544-555.

Daryanto, Y., Wee, H.M. and Astanti, R.D. (2019a). Three-echelon supply chain model considering carbon emission and item deterioration. Transportation Research Part E: Logistics and Transportation Review 122, pp. 368-383.

Daryanto, Y., Wee, H.M. and Widyadana, G.A. (2019b). Low carbon supply chain coordination for imperfect quality deteriorating items. Mathematics 7(3), Article No. 234.

Das, C. and Jharkharia, S. (2018). Low carbon supply chain: a stateof-the-art literature review. Journal of Manufacturing Technology Management 29(2), pp. 398-428.

Das, R., Shaw, K. and Irfan, M. (2020). Supply chain network design considering carbon footprint, water footprint, supplier's social risk, solid waste, and service level under the uncertain condition. Clean Technologies and Environmental Policy 22, pp. 337-370

Dwicahyani, A.R., Jauhari, W.A. and Jonrinaldi (2017). A regular production-remanufacturing inventory model for a twoechelon system with price-dependent return rate and environmental effects investigation. IOP Conference Series: Journal of Physics: Conference Series 855, 012013.

Fang, Y., Yu, Y., Shi, Y. and Liu, J. (2020). The effect of carbon tariffs on global emission control: A global supply chain model. Transportation Research Part E: Logistics and Transportation Review 133, Article No. 101818.

Ghosh, A., Sarmah, S.P. and Jha, J.K. (2018). Collaborative model for a two-echelon supply chain with uncertain demand under carbon tax policy. Sādhanā 43, Article No. 144.

Giri, B.C. and Chakraborty, A. (2011). Supply chain coordination for a deteriorating product under stock-dependent consumption rate and unreliable production process. International Journal of Industrial Engineering Computations 2(2), pp. 263-272.

Goyal, S.K., Huang, C.K. and Chen, K.C. (2003). A simple integrated production policy of an imperfect item for vendor and buyer. Production Planning \& Control 14(7), pp. 596602.

Hammami, R., Nouira, I. and Frein, Y. (2015). Carbon emissions in a multi-echelon production-inventory model with lead time constraints. International Journal of Production Economics 164, pp. 292-307.

Hariga, M., As'ad, R. and Shamayleh, A. (2017). Integrated economic and environmental models for a multi stage cold supply chain under carbon tax regulation. Journal of Cleaner Production 166, pp. 1357-1371.

Hua, G.W., Cheng, T.C.E., Zhang, Y., Zhang, J.L. and Wang, S.Y. (2016). Carbon-constrained perishable inventory management with freshness-dependent demand. International Journal of Simulation Modelling 15(3), pp. 542552.

Huang, C.K. (2002). An integrated vendor-buyer cooperative inventory model for items with imperfect quality. Production Planning \& Control 13(4), pp. 355-361.
Jaber, M.Y., Glock, C.H. and El-Saadany, A.M.A. (2013). Supply chain coordination with emissions reduction incentives. International Journal of Production Research 51(1), pp. 6982.

Jauhari, W.A., Pamuji, A.S. and Rosyidi, C.N. (2014). Cooperative inventory model for vendor-buyer system with unequal-sized shipment, defective items and carbon emission costs. International Journal of Logistics Systems and Management 19(2), pp. 163-186.

Jauhari, W.A. and Laksono, P.W. (2017). A joint economic lotsizing problem with fuzzy demand, defective items and environmental impacts. IOP Conference Series: Materials Science and Engineering 273, 012018.

Lee, S. and Kim, D. (2014). An optimal policy for a single vendor single-buyer integrated production-distribution model with both deteriorating and defective items. International Journal of Production Economics 147, pp. 161-170.

Khan, H. and Wisner, J.D. (2019). Supply chain integration, learning, and agility: Effects on performance. Operations and Supply Chain Management: An International Journal 12(1), pp. 14-23.

Khouja, M. (2003). The impact of quality considerations on material flow in two-stage inventory systems. International Journal of Production Research 41(7), pp.1533-1547.

Marchi, B., Zanoni, S., Zavanella, L.E. and Jaber, M.Y. (2019). Supply chain models with greenhouse gases emissions, energy usage, imperfect process under different coordination decisions. International Journal of Production Economics 211, pp. 145-153.

McKinnon, A. (2018). Decarbonizing logistics: Distributing goods in a low-carbon world. Kogan Page Ltd., London.

Mishra, M., Hota, S.K., Ghosh, S.K. and Sarkar, B. (2020). Controlling waste and carbon emission for a sustainable closed-loop supply chain management under a cap-and-trade strategy. Mathematics 8(4), Article No. 466.

Sarkar, B., Ahmed, W., Choi, S.B., and Tayyab, M. (2018). Sustainable inventory management for environmental impact through partial backordering and multi-trade-credit-period. Sustainability 10, Article No. 4761

Sarkar, B., Ganguly, B., Sarkar, M. and Pareek, S. (2016a). Effect of variable transportation and carbon emission in a threeechelon supply chain model. Transportation Research Part E: Logistics and Transportation Review 91(1), pp. 112-128.

Sarkar, B., Saren, S., Sarkar, M. and Seo, Y.W. (2016b). A Stackelberg game approach in an integrated inventory model with carbon-emission and setup cost reduction. Sustainability 8, Article No. 1244

Sarkar, B., Shaw, B.K., Kim, T., Sarkar, M. and Shin, D. (2017). An integrated inventory model with variable transportation cost, two-stage inspection, and defective items. Journal of Industrial \& Management Optimization 13(4), pp. 1975-1990.

Sarkis, J. (2012). A boundaries and flows perspective of green supply chain management. Supply Chain Management: An International Journal 17(2), pp. 202-216.

Shamayleh, A., Hariga, M., As'ad R. and Diabat, A. (2019). Economic and environmental models for cold products with time varying demand. Journal of Cleaner Production 212, pp. 847-863.

Tiwari, S., Daryanto, Y. and Wee, H.M. (2018). Sustainable inventory management with deteriorating and imperfect quality items considering carbon emissions. Journal of Cleaner Production 192, pp. 281-292.

Tseng, M.L., Islam, M.S., Karia, N., Fauzi, F.A. and Afrin, S. (2019). A literature review on green supply chain management: Trends and future challenges. Resources, Conservation and Recycling 141, pp. 145-162.

Tundys, B. (2018). Use of quantitative and qualitative methods for modelling green supply chains. Operations and Supply Chain Management: An International Journal 11(2), pp. 82-97. 
Wahab, M.I.M., Mamun, S.M.H. and Ongkunaruk, P. (2011). EOQ models for a coordinated two-level international supply chain considering imperfect items and environmental impact. International Journal of Production Economics 134(1), pp. 151-158.

Wang, K.J., Lin, Y.S. and Yu, J.C.P. (2011). Optimizing inventory policy for products with time-sensitive deteriorating rates in a multi-echelon supply chain. International Journal of Production Economics 130(1), pp. 66-76.

Wang, Q., Wu, J., Zhao, N. and Zhu, Q. (2019). Inventory control and supply chain management: A green growth perspective. Resources, Conservation \& Recycling 145, pp. 78-85.

Wangsa, I.D. (2017). Greenhouse gas penalty and incentive policies for a joint economic lot size model with industrial and transport emissions. International Journal of Industrial Engineering Computation 8(1), pp. 453-480.
Wee, H.M., Yu, J.C.P. and Wang, K.J. (2006). An integrated production-inventory model for deteriorating items with imperfect quality and shortage backordering considerations. In: Gavrilova et al. (eds) Computational Science and Its Applications - ICCSA 2006. Lecture Notes in Computer Science vol. 3982, pp. 885-897. Springer-Verlag, Berlin Heidelberg.

Yu, H.F. and Hsu, W.K. (2017). An integrated inventory model with immediate return for defective items under unequalsized shipments. Journal of Industrial and Production Engineering 34(1), pp. 70-77.

Zanoni, S., Mazzoldi, L. and Jaber, M.Y. (2014). Vendor-managed inventory with consignment stock agreement for single vendor-single buyer under the emission-trading scheme. International Journal of Production Research 52(1), pp.2031.

Yosef Daryanto is with the Department of Industrial Engineering, Universitas Atma Jaya Yogyakarta in Indonesia. He received his Bachelor's degree in Industrial Engineering from Universitas Atma Jaya Yogyakarta (Indonesia), MSc in International Technology Transfer Management from Technische Fachhochschule Berlin (Germany), and a Ph.D. from the Department of Industrial \& Systems Engineering, Chung Yuan Christian University (Taiwan). His current research interests include inventory control, supply chain management, and sustainability.

Hui-Ming Wee is a Distinguished Professor of Industrial \& Systems Engineering at Chung Yuan Christian University in Taiwan. He received his BSc (Hons) in Electrical and Electronic Engineering from Strathclyde University (UK), a MEng in Industrial Engineering and Management from the Asian Institute of Technology (AIT, Thailand), and a Ph.D. in Industrial Engineering from Cleveland State University, Ohio (USA). His research interests are in the field of production/inventory control, optimization, and supply chain management. 